\title{
Lactobacillus iners Is Associated with Vaginal Dysbiosis in Healthy Pregnant Women: A Preliminary Study
}

\author{
Nengneng Zheng $\mathbb{D}^{1},{ }^{1}$ Renyong Guo ${ }^{D},{ }^{2}$ Yinyu Yao $\left(\mathbb{D},{ }^{1}\right.$ Meiyuan Jin $\left(\mathbb{D},{ }^{1}\right.$ Yiwen Cheng $(\mathbb{D}){ }^{3}$ \\ and Zongxin Ling $\mathbb{D}^{3}$ \\ ${ }^{1}$ Department of Obstetrics, Tongde Hospital of Zhejiang Province, Hangzhou, Zhejiang 310012, China \\ ${ }^{2}$ Department of Laboratory Medicine, First Affiliated Hospital, College of Medicine, Zhejiang University, \\ Key Laboratory of Clinical In Vitro Diagnostic Techniques of Zhejiang Province, Hangzhou, Zhejiang 310003, China \\ ${ }^{3}$ Collaborative Innovation Center for Diagnosis and Treatment of Infectious Diseases, \\ State Key Laboratory for Diagnosis and Treatment of Infectious Diseases, \\ National Clinical Research Center for Infectious Diseases, The First Affiliated Hospital, School of Medicine, Zhejiang University, \\ Hangzhou, Zhejiang 310003, China
}

Correspondence should be addressed to Zongxin Ling; lingzongxin@zju.edu.cn

Received 31 May 2019; Accepted 3 October 2019; Published 23 October 2019

Academic Editor: Pengjun Shi

Copyright (c) 2019 Nengneng Zheng et al. This is an open access article distributed under the Creative Commons Attribution License, which permits unrestricted use, distribution, and reproduction in any medium, provided the original work is properly cited.

\begin{abstract}
Vaginal dysbiosis has been identified to be associated with adverse pregnancy outcomes, such as preterm delivery and premature rupture of membranes. However, the overall structure and composition of vaginal microbiota in different trimesters of the pregnant women has not been fully elucidated. In this study, the physiological changes of the vaginal microbiota in healthy pregnant women were investigated. A total of 83 healthy pregnant participants were enrolled, who are in the first, second, or third pregnancy trimester. Quantitative real-time PCR was used to explore the abundant bacteria in the vaginal microbiota. No significant difference in the abundance of Gardnerella, Atopobium, Megasphaera, Eggerthella, Leptotrichia/Sneathia, or Prevotella was found among different trimesters, except Lactobacillus. Compared with the first pregnancy trimester, the abundance of $L$. iners decreased in the second and third trimester while the abundance of L. crispatus was increased in the second trimester. Moreover, we also found that vaginal cleanliness is correlated with the present of Lactobacillus, Atopobium, and Prevotella and leukocyte esterase is associated with Lactobacillus, Atopobium, Gardnerella, Eggerthella, Leptotrichia/Sneathia, and Prevotella. For those whose vaginal cleanliness raised or leukocyte esterase became positive, the richness of $L$. iners increased, while that of $L$. crispatus decreased significantly. Our present data indicated that the altered vaginal microbiota, mainly Lactobacillus, could be observed among different trimesters of pregnancy and L. iners could be considered as a potential bacterial marker for evaluating vaginal cleanliness and leukocyte esterase.
\end{abstract}

\section{Introduction}

The vaginal microbiota consist of a variety of species, including both anaerobic and aerobic microorganisms [1]. These commensal microorganisms in the vagina provide beneficial effects against opportunistic and pathogenic bacteria, constituting the first line of defense against invasive microorganisms [2]. Some of the species such as L. crispatus, L. gasseri, and L. jensenii take function by lowering the $\mathrm{pH}$ and production of large amounts of lactic acid and bactericide compounds, such as hydrogen peroxide $\left(\mathrm{H}_{2} \mathrm{O}_{2}\right)$ and bacteriocins $[3,4]$, which prevent possible pathogenic or opportunistic pathogenic bacteria and ensure vaginal epithelial homeostasis.

Preterm delivery is known to be one of the main causes of perinatal mortality and morbidity worldwide [5]. Generally, it will result in very low birth weight, prolonged stay in hospital, increased risk of chronic lung disease, and even cerebral palsy. Besides, premature rupture of membranes (PROM) is also a dangerous complication. In the event of PROM, the uterine cavity, placenta, and fetus are exposed to ascending infection 
and increased risk of chorioamnionitis and funisitis, which are both associated with poor maternal and neonatal outcomes [6-10]. Recently, lower genital tract infection has been recognized as one of the more important risk factors associated with preterm delivery and PROM, especially in healthy nulliparous women [11]. Dysbiosis of vaginal microbiome has been recognized as a potential cause of adverse pregnancy outcomes, if they are not dominated by Lactobacillus [12-15]. However, the influence of vaginal dysbiosis on preterm delivery and PROM still remains unknown.

Healthy pregnancy is characterized by a temporary dynamic shift towards stable, reduced richness and low diversity in the community structures dominated by Lactobacillus spp. which aids in the prevention of pathogenic bacteria, different from the vaginal microbiota composition of nonpregnant women $[16,17]$. Bacterial vaginosis (BV) is a condition in which the vaginal microbiota suffer a reduction in several species of probiotic Lactobacillus and an increase in the presence of anaerobes (Gardnerella vaginalis, Atopobium vaginae, and Mobiluncus sp.), which has been shown in our previous studies $[18,19]$. It is hypothesized that colonization of the pathogenic bacteria in the vagina activates the local and upper (cervical and fetal membrane) innate immune system, drives an inflammatory cascade, and leads to a remodeling and disruption of membrane architecture and preterm delivery or PROM $[20,21]$.

Currently, cultivation-independent molecular approaches are favored for overcoming the difficult cultivation conditions such as nutrition and anaerobic requirements [22]. Thus, they have been used to demonstrate greater vaginal microbial diversity than that recognized previously. Several cultivationindependent species, such as $L$. iners and A. vaginae, have been identified as important elements of the vaginal microbiota as they are found across Lactobacillus-dominated and non-Lactobacillus-dominated vaginal microbiota groups $[23,24]$. Thus, a deeper understanding of the composition and structure of the vaginal microbiota in healthy pregnant women is essential for fully elucidating the etiology of vaginal diseases as well as for the prevention and treatment of such diseases. Furthermore, there is an urgent need for a better understanding of when the clinical relevance of some bacteria became increasingly apparent, due to a change in either relative or absolute abundance.

The aim of this study was to investigate the vaginal microbiota in the first, second, and third pregnancy trimester in healthy pregnant women using a cultivation-independent approach. The exploration of the vaginal microbiota in these women provides a theoretical basis that may help to prevent vaginal infections during pregnancy and reduce preterm delivery and PROM.

\section{Materials and Methods}

2.1. Subjects' Recruitment. Healthy pregnant women, without abnormal vaginal discharge, were randomly enrolled, when they came to the Department of Obstetrics of Tongde Hospital in Zhejiang Province (Zhejiang, China) for routine medical examination between July and November 2016. A total of 83 subjects, aged $30.0 \pm 4.6$ years, were studied across three time points, with 33 between 5 and 10 weeks' gestation in the first trimester, 24 between 20 and 27 weeks' gestation in the second trimester, and 26 between 37 and 39 weeks' gestation in the third trimester. The following criteria were used to exclude subjects: a history of preterm delivery; previous multiple pregnancies; placenta previa or vaginal bleeding; candidiasis, BV, or trichomoniasis; use of antibiotics, probiotics, prebiotics, or synbiotics in the previous month; cervical incompetence or suspected uterine malformation; vaginal intercourse within the last 3 days; or were immunocompromised. Informed written consent was obtained from each of the participants before enrollment. This research was conducted in agreement with the ethical principles of the Declaration of Helsinki, and the study protocol was approved by the Ethics Committee of the Tongde Hospital of Zhejiang Province.

2.2. Sample Collection. Three swabs of vaginal secretions were taken from the posterior wall of the vaginal fornix at an outpatient service when these participants underwent speculum examination. Two of the swabs were applied onto a slide for determination of vaginal $\mathrm{pH}$ and vaginal infection status. The remaining vaginal swab was covered, placed on ice, and used for bacterial genomic DNA extraction. Vaginal $\mathrm{pH}$ was measured using a pH strip (Sanaisi Company, Shanghai, China). Vaginal infection status was determined by examining a wet mount smear in potassium hydroxide for detection of candidiasis and in saline for detection of motile trichomonas and clue cells. BV diagnosis was assessed according to Amsel clinical criteria [25]. $\mathrm{H}_{2} \mathrm{O}_{2}$ and leukocyte esterase were analyzed according to the manual method of the BV union diagnosis kits (Lizhu Company, Zhuhai, Guangdong, China). Vaginal cleanliness was evaluated according to morphological observations (Table S1) [26]. The criteria of vaginal cleanliness were as follows [27]: Grade I was a large number of large Gram-positive rods (indicative of Lactobacillus spp.), vaginal epithelial cells, and no other bacteria observed with WBC 0-5/HP under microscopy. Grade II was some Lactobacillus spp. and vaginal epithelial cells, some pus cells, and other bacteria observed under microscopy with WBC 10-15/HP. Grade III was a small amount of Lactobacillus spp., a large number of pus cells, and other bacteria observed under microscopy with WBC 15-30/HP. Grade IV was no Lactobacillus spp. but pus cells and other bacteria observed under microscopy with WBC more than 30/HP. Grades I-II mean normal vaginal cleanliness, while grades IIIIV mean abnormal vaginal cleanliness with inflammation. The vaginal swabs taken for bacterial genomic DNA extraction were transferred to the laboratory immediately and stored at $-80^{\circ} \mathrm{C}$ until analyzed. Additionally, hospital records were reviewed following delivery to determine pregnancy outcome, including preterm birth, premature rupture of membranes, or preterm premature rupture of membranes.

2.3. Total Bacterial Genomic DNA Extraction. The bacterial cells retrieved on swabs were submerged in $1 \mathrm{~mL}$ of ice-cold phosphate-buffered saline ( $\mathrm{pH}$ 7.5) and vigorously agitated to dislodge cells. The suspension was then transferred to a 
tube containing $100 \mathrm{mg}$ of glass beads (Promega Corporation, Madison, WI, USA) and placed into a FastPrep FP120 instrument (Thermo Scientific, Pittsburgh, PA, USA) to disrupt the cell membranes. The suspension was then centrifuged at $17,000 \mathrm{~g}$ for $10 \mathrm{~min}$, resuspended in $400 \mu \mathrm{L}$ of lysozyme, and incubated for $1 \mathrm{~h}$ at $37^{\circ} \mathrm{C}$. Subsequently, $500 \mu \mathrm{L}$ of cell lysis solution was added and warmed for an additional $30 \mathrm{~min}$ at $37^{\circ} \mathrm{C}$. The reaction solution was then centrifuged for $10 \mathrm{~min}$ at $12,000 \mathrm{~g}$. After removing the supernatant, $180 \mu \mathrm{L}$ of lysis buffer (buffer ATL) and $25 \mu \mathrm{L}$ of proteinase $\mathrm{K}$ were added to the sample and incubated for $60 \mathrm{~min}$ at $55^{\circ} \mathrm{C}$. The QIAamp DNA Mini Extraction Kit (QIAGEN, Hilden, Germany) was then used for the isolation of the genomic DNA according to the manufacturer's instructions. One sterile cotton swab was used as a negative control alongside the patient specimens. The concentration of extracted DNA was determined using a Smart-Spec Plus spectrophotometer (Bio-Rad Laboratories, Hercules, CA, USA). Its integrity and size were checked by $1.0 \%$ agarose gel electrophoresis, containing $0.5 \mathrm{mg} / \mathrm{ml}$ ethidium bromide. All DNA was stored at $-20^{\circ} \mathrm{C}$ before analysis.

2.4. Quantitative Real-Time PCR ( $q P C R$ ) Analysis. The ABI 7900 Fast Real-Time PCR instrument and Sequence Detection Software version 1.6.3 (Applied Biosystems, Foster City, CA, USA) were used to perform qPCR on all subjects, to determine accurate copy numbers of bacteria in the vaginal specimens. The following species-specific primer sets were chosen to quantify total bacteria in the samples, Lactobacillus genus, L. crispatus, L. jensenii, L. iners, G. vaginalis, A. vaginae, Eggerthella sp., Leptotrichia/Sneathia sp. Megasphaera sp., and Prevotella sp. (Table 1) [19]. The optimal reaction conditions and parameters were obtained by adjusting the concentration of primers, reaction temperature, and the cycles of amplification. Each qPCR contained $1 \mu \mathrm{L}$ of template DNA, $12.5 \mu \mathrm{L}$ of $2 \times$ Takara Perfect Real Time master mix, $0.3 \mu \mathrm{L}$ of a $10 \mu \mathrm{M}$ F/R primer mix, and $10.9 \mu \mathrm{L}$ of water. The reaction parameters were as follows: 1 cycle of predenaturation for $3 \mathrm{~min}$ at $95^{\circ} \mathrm{C}, 40$ repeated cycles of denaturation for $30 \mathrm{~s}$ at $94^{\circ} \mathrm{C}$, annealing for $30 \mathrm{~s}$, extension for $30 \mathrm{~s}$ at $72^{\circ} \mathrm{C}$, and a final extension step for $5 \mathrm{~min}$ at $72^{\circ} \mathrm{C}$. At the end of the qRT$\mathrm{PCR}$, the specificity of the products produced was confirmed through a melting curve analysis, whereby the PCR products were slowly heated from $55^{\circ} \mathrm{C}$ to $95^{\circ} \mathrm{C}$ in $1.0^{\circ} \mathrm{C}$ increments with continuous fluorescence collection.

Serially diluted standards of plasmid DNA ( 1 to $10^{8}$ copies) containing the respective amplicon for each primer pair were run on the same plate to construct a standard curve, in order to obtain a corresponding target DNA copy number of each species in each $\mu \mathrm{L}$ of crude DNA template. All samples including nontemplate controls were assayed three times on separate plates. Aliquots $(4 \mu \mathrm{L})$ of the realtime PCR products with each of the species-specific primer pairs were examined by $1.5 \%$ agarose gel electrophoresis containing $0.5 \mathrm{mg} / \mathrm{mL}$ ethidium bromide.

2.5. Statistical Analysis. The data were expressed as the mean and standard deviation for continuous variables and as absolute and relative frequencies for categorical variables. The abundance of genus-specific bacteria was expressed as the percentage of the accurate copy numbers of the individual bacterial subgroups and total bacteria in the samples. The mean values of each item for continuous variables between two groups were compared using the Mann-Whitney $U$ test, whereas differences among the three groups were analyzed using the Kruskal-Wallis $H$ test. Nonparametric chi-square tests were used to compare categorical variables. Spearman's rank correlation was used to evaluate the relationship between parameters. All statistical tests were performed using SPSS, version 19.0 (SPSS Inc., Chicago, IL, USA), and any $p$ value $<0.05$ was considered statistically significant.

\section{Results}

3.1. Characteristics of the Subjects. In this study, vaginal samples of 83 healthy pregnant women were analyzed. The varying gestational ages of the women screened were compared in terms of clinical characteristics (e.g., maternal age, gravity, and parity), laboratory characteristics (vaginal $\mathrm{pH}$, vaginal cleanliness, and $\mathrm{H}_{2} \mathrm{O}_{2}$ levels), and the presence of leukocyte esterase (Table 2). There was no difference in the maternal ages, gravidity, or parity among the three trimester groups, indicating that the participants in each of the different groups had similar clinical characteristics and were therefore comparable throughout this study. Comparing vaginal cleanliness and leukocyte esterase, it was found that they were significantly higher in women in the first trimester than in the second $(p=0.001)$ and third trimester $(p<0.001)$. However, vaginal $\mathrm{pH}$ and $\mathrm{H}_{2} \mathrm{O}_{2}$ levels showed no difference among trimesters.

\subsection{Distribution of Vaginal Bacteria in Pregnant Women.} In this study, using qRT-PCR, seven known abundant genera (Lactobacillus, Gardnerella, Atopobium, Megasphaera, Eggerthella, Leptotrichia/Sneathia, and Prevotella) were analyzed. The abundance of Gardnerella, Atopobium, Megasphaera, Eggerthella, Leptotrichia/Sneathia, and Prevotella was significantly different among the three trimesters $(p>0.05)$. The genus Lactobacillus constituted the major proportion of the vaginal microbiota in healthy pregnant women, which was consistent with previous studies $[34,36,37]$. L. jensenii, L. iners, and L. crispatus were the most frequent species [37-39]. Among them, the abundance of $L$. iners and L. crispatus was significantly different among the trimesters. We also found that L. iners decreased significantly in women in the second and third trimester when compared with women in the first trimester $(p<0.001)$, while L. crispatus significantly increased in the second trimester $(p=0.030)$ (Figure 1$)$. However, the relative abundance of $L$. jensenii was unchanged obviously among the three trimesters $(p=0.633$; Table 3$)$.

3.3. Correlation of Vaginal Bacteria with Vaginal Cleanliness and Leucocyte Esterase. Vaginal cleanliness and leukocyte esterase varied significantly throughout the pregnancy trimester. Spearman's rank correlation was used to examine 
TABLE 1: Species-specific primer sets for detection of vaginal bacteria by quantitative real-time PCR.

\begin{tabular}{|c|c|c|c|c|c|}
\hline PCR specificity & Primer & Sequence $\left(5^{\prime}-3^{\prime}\right)$ & Annealing temp. & Amplicon size (bp) & Reference \\
\hline All bacteria & $\begin{array}{c}\text { Bac27F } \\
\text { EUB338R-I }\end{array}$ & $\begin{array}{c}\text { AGAGTTTGATCCTGGCTCAG } \\
\text { GCTGCCTCCCGTAGGAGT }\end{array}$ & $65^{\circ} \mathrm{C}$ & 312 & {$[28]$} \\
\hline Lactobacillus genus & $\begin{array}{l}\text { Bact-0011 } \\
\text { Lab-0677 }\end{array}$ & $\begin{array}{c}\text { AGAGTTTGATYMTGGCTCAG } \\
\text { CACCGCTACACATGGAG }\end{array}$ & $62^{\circ} \mathrm{C}$ & 667 & [29] \\
\hline L. crispatus & $\begin{array}{l}\text { Lcris-F } \\
\text { Lcris-R }\end{array}$ & $\begin{array}{c}\text { AGCGAGCGGAACTAACAGATTTAC } \\
\text { AGCTGATCATGCGATCTGCTT }\end{array}$ & $65^{\circ} \mathrm{C}$ & 154 & {$[30]$} \\
\hline L. jensenii & $\begin{array}{l}\text { Ljens-F } \\
\text { Ljens-R }\end{array}$ & $\begin{array}{c}\text { AAGTCGAGCGAGCTTGCCTATAGA } \\
\text { CTTCTTTCATGCGAAAGTAGC }\end{array}$ & $60^{\circ} \mathrm{C}$ & 162 & {$[31]$} \\
\hline L. iners & $\begin{array}{l}\text { Liners-F } \\
\text { Liners- } \mathrm{R}\end{array}$ & $\begin{array}{c}\text { CTCTGCCTTGAAGATCGGAGTGC } \\
\text { ACAGTTGATAGGCATCATCTG }\end{array}$ & $65^{\circ} \mathrm{C}$ & 155 & {$[31]$} \\
\hline Atopobium vaginae & $\begin{array}{l}\text { AV-F } \\
\text { AV-R }\end{array}$ & $\begin{array}{l}\text { TAGGTCAGGAGTTAAATCTG } \\
\text { TCATGGCCCAGAAGACCGCC }\end{array}$ & $62^{\circ} \mathrm{C}$ & 156 & {$[32]$} \\
\hline Gardnerella vaginalis & $\begin{array}{l}\text { GV1-F } \\
\text { GV3-R }\end{array}$ & $\begin{array}{c}\text { TTACTGGTGTATCACTGTAAGG } \\
\text { CCGTCACAGGCTGAACAGT }\end{array}$ & $62^{\circ} \mathrm{C}$ & 332 & {$[33]$} \\
\hline Eggerthella & $\begin{array}{l}\text { Egger-621F } \\
\text { Egger-859R }\end{array}$ & $\begin{array}{c}\text { AACCTCGAGCCGGGTTCC } \\
\text { TCGGCACGGAAGATGTAATCT }\end{array}$ & $60^{\circ} \mathrm{C}$ & 239 & {$[34]$} \\
\hline Leptotrichia/Sneathia & $\begin{array}{l}\text { Lepto-395F } \\
\text { Lepto-646R }\end{array}$ & $\begin{array}{l}\text { CAATTCTGTGTGTGTGAAGAAG } \\
\text { ACAGTTTTGTAGGCAAGCCTAT }\end{array}$ & $60^{\circ} \mathrm{C}$ & 252 & {$[34]$} \\
\hline Megasphaera type I & $\begin{array}{l}\text { MegaE-456F } \\
\text { MegaE-667R }\end{array}$ & $\begin{array}{l}\text { GATGCCAACAGTATCCGTCCG } \\
\text { CCTCTCCGACACTCAAGTTCGA }\end{array}$ & $64^{\circ} \mathrm{C}$ & 212 & {$[34]$} \\
\hline Prevotella & $\begin{array}{l}\text { Prevo-F } \\
\text { Prevo-R }\end{array}$ & $\begin{array}{c}\text { CCAGCCAAGTAGCGTGCA } \\
\text { TGGACCTTCCGTATTACCGC }\end{array}$ & $60^{\circ} \mathrm{C}$ & 151 & {$[35]$} \\
\hline
\end{tabular}

TABLE 2: Clinical and laboratory characteristics of the participants.

\begin{tabular}{lccc}
\hline Parameters & $\begin{array}{c}\text { Participants in 1st trimester } \\
(n=33)\end{array}$ & $\begin{array}{c}\text { Participants in 2nd trimester } \\
(n=24)\end{array}$ & $\begin{array}{c}\text { Participants in 3rd trimester } \\
(n=26)\end{array}$ \\
\hline Age (years) & $28.30(5.35)$ & $29.50(3.91)$ & $29.35(4.03)$ \\
Gravidity & $0.88(0.96)$ & $1.21(1.22)$ & $1.31(1.62)$ \\
Parity & $0.55(0.66)$ & $0.50(0.51)$ & $0.42(0.50)$ \\
PH & $4.2(0.3)$ & $4.0(0.2)$ & $4.1(0.2)$ \\
Cleanliness $(1-2 / 3-4)$ & $18 / 15$ & $23 / 1$ & 0.604 \\
$\mathrm{H}_{2} \mathrm{O}_{2}(<2 / \geq 2)$ & $5 / 28$ & $0 / 24$ & 0.832 \\
Leucocyte esterase & $14 / 19$ & $0 / 24$ & 0.118 \\
$(\mathrm{P} / \mathrm{N})$ & & & $\mathbf{0 . 0 0 1}$ \\
\hline
\end{tabular}

All data are mean (standard deviation). P, positive; N, negative.

the relationship between abundant vaginal microbiota and the two indicators including vaginal cleanliness and leukocyte esterase (Table 4). We found that vaginal cleanliness was significantly correlated with the presence of Lactobacillus, Atopobium, and Prevotella instead of other bacteria genus. However, all abundant bacteria except for Megasphaera $(p<0.05)$ were altered significantly between leukocyte esterase positive and negative. Additionally, it was interesting to find that the relative abundance of $L$. iners increased with raised vaginal cleanliness grade and positve leukocyte esterase, but $L$. crispatus did not show such similar changing patterns.

3.4. Relationship between Vaginal $\mathrm{pH}$ and Vaginal Abundant Bacteria. In our present study, vaginal $\mathrm{pH}$ was maintained at a low level in these pregnant women and was not changed significantly across the three trimesters. Normally, Lactobacilli acidify the vagina with lactic acid, while the overgrowth of those vaginal pathogenic bacteria may lead to the elevation of vaginal $\mathrm{pH}$. We used Spearman's rank correlations to investigate the relationships between the relative abundance of genus-specific vaginal bacteria and vaginal $\mathrm{pH}$. As shown in Figure 2, the vaginal $\mathrm{pH}$ increased when Lactobacillus, and more specifically L. crispatus decreased when the vaginal $\mathrm{pH}$ increased. However, the vaginal $\mathrm{pH}$ also was positively correlated with $L$. jensenii, $L$. iners, A. vaginae, and G. vaginalis.

\section{Discussion}

Vaginal cleanliness and leukocyte esterase have been proven previously to be associated with genital inflammation [27]. In this study, it was discovered that vaginal cleanliness and leukocyte esterase were significantly higher in women who were in the first trimester instead of the second and third trimester. Although this result cannot fully illustrate that these two inflammatory markers change spontaneously as 


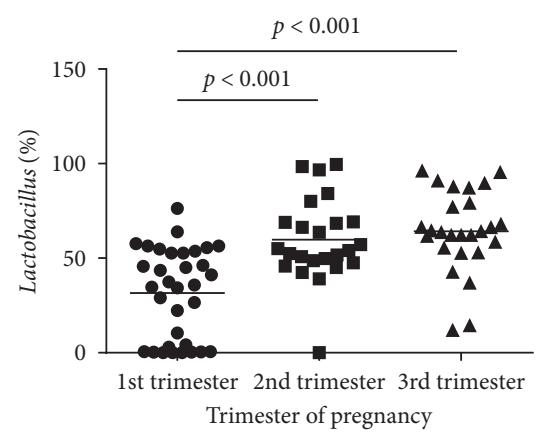

(a)

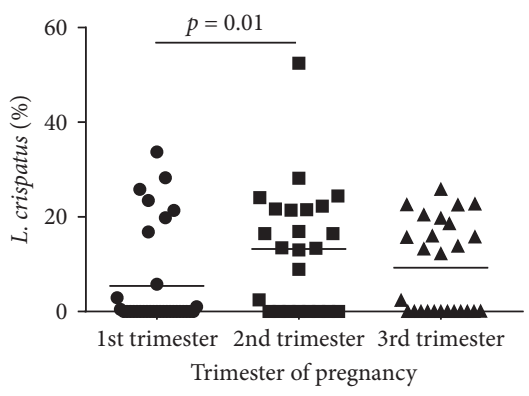

(b)

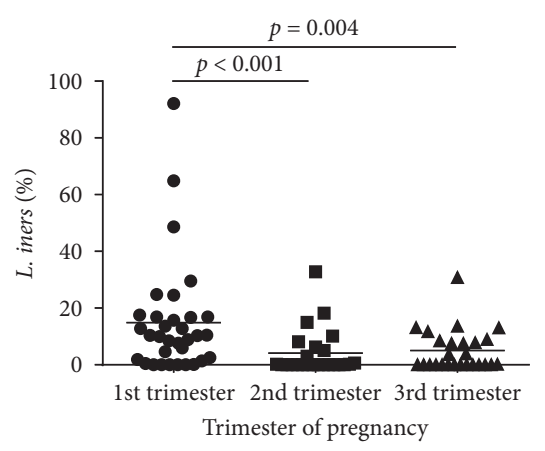

(c)

Figure 1: Comparison of the relative abundance of (a) Lactobacillus, (b) L. crispatus, and (c) L. iners in 83 asymptomatic pregnant women according to their trimester of pregnancy. Data are expressed as scatter plots, in which the horizontal lines illustrate the mean value of each genus-specific bacterium.

TABle 3: Comparison of the relative abundance of vaginal bacteria by quantitative real-time PCR according to trimesters of pregnancy.

\begin{tabular}{|c|c|c|c|c|}
\hline Species & $\begin{array}{l}\text { Participants in 1st trimester } \\
(n=33)\end{array}$ & $\begin{array}{l}\text { Participants in } 2 \text { nd trimester } \\
\qquad(n=24)\end{array}$ & $\begin{array}{l}\text { Participants in 3rd trimester } \\
(n=26)\end{array}$ & $\begin{array}{c}p \\
\text { value }\end{array}$ \\
\hline Lactobacillus genus (\%) & $31.57(23.94)$ & $59.80(21.96) \mathrm{b}$ & $64.14(21.61) b$ & $<0.001$ \\
\hline L. jensenii $(\%)^{\mathrm{a}}$ & $0.07(0.32)$ & $0.43(2.07)$ & $0.27(1.31)$ & 0.633 \\
\hline L. crispatus $(\%)^{\mathrm{a}}$ & $5.74(10.39)$ & $13.21(12.96) \mathrm{c}$ & $9.67(10.47)$ & 0.030 \\
\hline L. iners $(\%)^{\mathrm{a}}$ & $14.86(19.74)$ & $4.16(7.97) \mathrm{d}$ & $5.02(7.24) \mathrm{d}$ & $<0.001$ \\
\hline Atopobium vaginae (\%) & $1.21(3.17)$ & $2.63(12.86)$ & $0.03(0.16)$ & 0.897 \\
\hline $\begin{array}{l}\text { Gardnerella } \\
\text { vaginalis }(\%)\end{array}$ & $0.10(0.24)$ & $0.08(0.34)$ & $2.49(12.67)$ & 0.944 \\
\hline Eggerthella (\%) & $0.05(0.21)$ & $0.00(0.00)$ & $0.00(0.00)$ & 0.466 \\
\hline $\begin{array}{l}\text { Leptotrichial } \\
\text { Sneathia (\%) }\end{array}$ & $0.04(0.12)$ & $0.00(0.00)$ & $0.00(0.00)$ & 0.432 \\
\hline Megasphaera type (\%) & $0.29(0.80)$ & $0.02(0.10)$ & $0.02(0.09)$ & 0.569 \\
\hline Prevotella $(\%)$ & $0.19(0.45)$ & $0.00(0.01)$ & $0.09(0.45)$ & 0.169 \\
\hline
\end{tabular}

All data are mean (standard deviation). ${ }^{a}$ The relative abundance of L. crispatus, L. jensenii, and L. iners was compared to the copy number of Lactobacillus genus; ${ }^{\text {b }}$ compared with 1 st trimester, $p<0.001$; $^{c}$ compared with 1 st trimester, $p<0.05$; ${ }^{d}$ compared with 1st trimester, $p<0.01$.

TABLE 4: Correlation of the relative abundance of vaginal bacteria with vaginal cleanliness and leucocyte esterase.

\begin{tabular}{|c|c|c|c|c|c|c|}
\hline \multirow{2}{*}{ Vaginal bacteria } & \multicolumn{3}{|c|}{ Vaginal cleanliness } & \multicolumn{3}{|c|}{ Leucocyte esterase } \\
\hline & $1-2(n=63)$ & $3-4(n=20)$ & $p$ value & Negative $(n=65)$ & Positive $(n=18)$ & $p$ value \\
\hline Lactobacillus genus (\%) & $55.00(25.14)$ & $34.10(27.18)$ & 0.002 & $55.42(23.86)$ & $30.13(29.06)$ & 0.001 \\
\hline L. jensenii (\%) & $10.68(11.91)$ & $4.27(8.67)$ & 0.072 & $10.39(11.84)$ & $4.61(9.09)$ & 0.241 \\
\hline L. crispatus $(\%)$ & $0.30(1.53)$ & $0.02(0.22)$ & 0.873 & $0.29(1.51)$ & $0.03(0.47)$ & 0.220 \\
\hline L. iners $(\%)$ & $6.18(13.04)$ & $16.56(16.49)$ & $<0.001$ & $6.18(12.79)$ & $17.73(17.15)$ & $<0.001$ \\
\hline Atopobium vaginae (\%) & $0.51(2.46)$ & $1.09(2.57)$ & 0.044 & $0.49(2.42)$ & $1.23(2.67)$ & 0.004 \\
\hline Gardnerella vaginalis (\%) & $0.05(0.22)$ & $0.20(0.43)$ & 0.133 & $0.04(0.22)$ & $0.23(0.44)$ & 0.023 \\
\hline Eggerthella (\%) & $0.00(0.01)$ & $0.08(0.84)$ & 0.194 & $0.00(0.01)$ & $0.09(1.02)$ & 0.006 \\
\hline Leptotrichia/Sneathia (\%) & $0.01(0.11)$ & $0.04(0.21)$ & 0.496 & $0.00(0.01)$ & $0.06(0.41)$ & 0.032 \\
\hline Megasphaera type (\%) & $0.07(0.23)$ & $0.30(0.75)$ & 0.686 & $0.06(0.43)$ & $0.36(1.32)$ & 0.097 \\
\hline Prevotella (\%) & $0.02(0.18)$ & $0.36(1.46)$ & 0.004 & $0.01(0.02)$ & $0.45(1.36)$ & 0.002 \\
\hline
\end{tabular}

All data are mean (standard deviation). The abundance of vaginal bacteria relative to total bacteria gene copy number according to vaginal cleanliness and leucocyte esterase was compared. ${ }^{a}$ The relative abundance of L. crispatus, L. jensenii, and L. iners was compared to the copy number of Lactobacillus genus.

pregnancy progressed, previous studies indicated that this phenomenon may be possible. Waters et al. performed a longitudinal investigation and found that most women who were BV positive in early pregnancy became BV negative in the third trimester [40]. Duff et al. have reported that BV disappeared spontaneously between 15 and 36 weeks in $11 \%$ of pregnant patients without any therapies or interventions
[41]. However, further longitudinal studies are needed to explore the definite relationship between the dynamic vaginal microbiota and the progress of pregnancy.

Vaginal $\mathrm{pH}$ is another known indicator of vaginal health which is commonly used for the diagnosis of genital infections. The vaginal $\mathrm{pH}$ significantly increases when $\mathrm{BV}$ or trichomoniasis vaginitis is present and it decreases when 


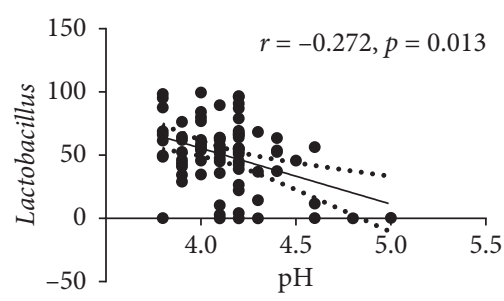

(a)

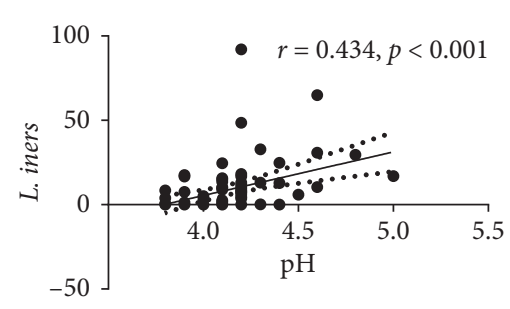

(d)

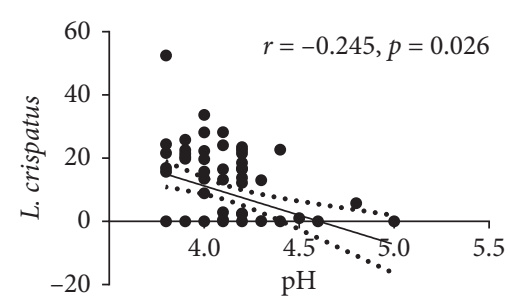

(b)

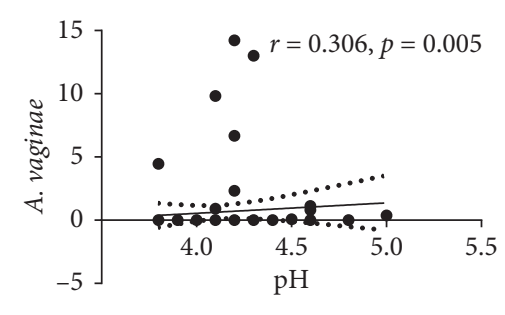

(e)

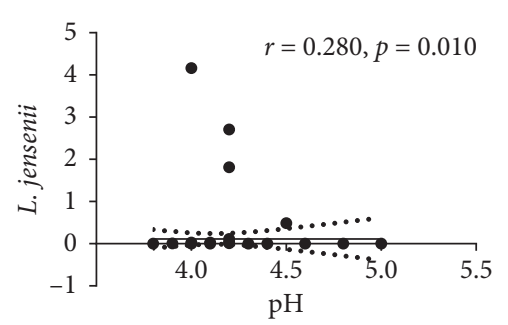

(c)

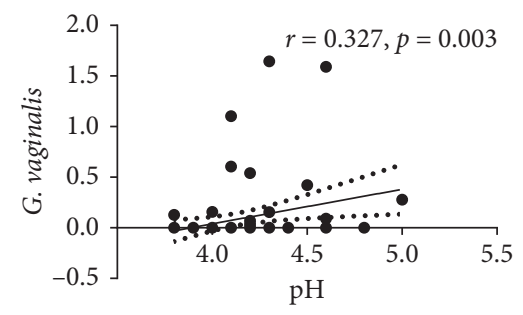

(f)

Figure 2: Correlation between the relative abundance of genus-specific bacteria and vaginal $\mathrm{pH}$ in 83 asymptomatic pregnant women. Relationships among the vaginal pH with (a) Lactobacillus, (b) L. crispatus, (c) L. jensenii, (d) L. iners, (e) A. vaginae, and (f) G. vaginalis are shown as scatter plots and regression lines. The coefficient is taken from Spearman's correlation test.

Candida vaginitis occurs $[42,43]$. However, vaginal $\mathrm{pH}$ did not seem to be closely associated with changes in the vagina microecosystem strongly according to the results. Furthermore, $\mathrm{H}_{2} \mathrm{O}_{2}$ is known as an important factor of vaginal health and is mostly produced by Lactobacillus and acts as a certain antibacterial compound which can protect against genital tract pathogens. Our data indicated that there was no significant difference in the presence of $\mathrm{H}_{2} \mathrm{O}_{2}$ among the three trimesters $(p=0.125)$, indicating that it could help to maintain vaginal homeostasis in the normal status. Of course, the bacterial interactions in the pregnancy-related vaginal microbiota are complex and are not simply related to the presence or absence of $\mathrm{H}_{2} \mathrm{O}_{2}$-producing Lactobacillus [44].

The vaginal microbial community is typically characterized by abundant lactobacilli. In our study, two species of Lactobacillus, such as L. iners and L. crispatus, were found to be significantly different among the three trimesters. L. iners was found to be significantly decreased whereas L. crispatus was found to be significantly increased in women in the second and third trimester compared with the first trimester. Besides, we observed that vaginal cleanliness and leukocyte esterase were significantly affected by $L$. iners but not by $L$. crispatus, which was consistent with the previous study [45]. With recent advances in culture-independent community profiling, the nutritionally fastidious $L$. iners is emerging as a dominant organism, present in both healthy and lactobacillideficient aberrant vaginal environments, suggesting that $L$. iners is very flexible and can easily adapt to the fluctuating vaginal niche [46-48]. Therefore, the existence of $L$. iners may not suppress the proliferation of other potentially harmful bacteria in the vagina [49]. L. iners has been thought to be a precursor to being susceptible to adverse pregnant sequelae [50]. Simultaneously, L. crispatus has been previously suggested to be linked to healthy microbiota, a healthy pregnancy, and a term delivery and to the absence of vaginal infection or inflammation [51]. In this work, we had identified a positive correlation between inflammatory laboratory characteristics and $L$. iners.

In fact, there is a lot of controversy over whether L. iners is advantageous or detrimental for the host microbiota. Gajer et al. observed that the vaginal communities dominated by $L$. crispatus changed into a community dominated by $L$. iners during menstruation [52]. Their findings indicate that $L$. iners may help in the recovery of lactobacilli-dominant vaginal microbiota, supporting the notion that $L$. iners is a beneficial species [53]. Most women with an $L$. iners-dominated vaginal community will deliver at term with no adverse pregnancy outcome [50,51]. Previous studies have found that $L$. iners may be a beneficial vaginal bacterium which showed beneficial effects in several mechanisms. It has been proposed that L. iners activates Toll-like receptor signaling in epithelial cells, elevates the levels of heat-shock protein 70 , and inhibits autophagy [54, 55]. This process could combat a nonphysiological threat and maintain and promote a return to healthier conditions [56]. This would be by inducing the innate immune system in the vaginal epithelial cells, preventing harmful bacteria from obtaining important nutrients such as iron, and inhibiting their continual growth [45]. However, several studies indicated that $L$. iners offers less protection against vaginal dysbiosis [45]. In the present study, we also found that $L$. iners was more responsive to the dysbiosis of vaginal microbiota when compared to L. crispatus. Due to the significant complex and diverse individual discrepancies of the vaginal microbiota, more studies are required to make clear whether $L$. iners can be used as a novel biomarker to detect the presence or prognosis of vaginal inflammation and guide clinical treatment.

Our research had also explored several anaerobic microorganisms, Gardnerella, Atopobium, Megasphaera, Eggerthella, Leptotrichia/Sneathia, and Prevotella, which were considered 
as the vaginal pathogenic community. Our previous studies have found that these bacteria in the vaginal pathogenic community increased significantly in patients with BV accompanying with the depletion of Lactobacillus $[19,57,58]$, which is highly accurate for BV diagnosis. However, the abundance of these bacteria was not changed significantly among the three trimesters in our present study. Previous studies have shown that G. vaginalis (belonging to Actinobacteria) plays an important role in the development of BV $[19,34]$. Another genus in Actinobacteria, Atopobium, has been suggested to be even more specific than G. vaginalis for the diagnosis of BV (77\% and 35\%, respectively) [59]. Additionally, the presence of Eggerthella has also been considered as an independent risk factor for BV scores (Nugent score $\geq 7$ ) [31]. Other members such as Prevotella (belonging to Bacteroidetes), Megasphaera (especially Megasphaera typeI), and Leptotrichia/Sneathia (belonging to Fusobacteria) also appeared to have a strong positive association with $\mathrm{BV}$, although previous research could not detect these genera in all BV samples [19, 34, 60, 61]. However, the clinical significance of these genera associated with $\mathrm{BV}$ in the vaginal ecosystem was still unknown. In this study, we found these bacteria in subjects who did not have BV, and therefore, this may suggest that these species may not be a specific marker for BV. Of course, these bacteria in the vaginal microbiota were interacted with each other closely. Previous study also found a clear negative association between $L$. iners and $L$. gasseri and between A. vaginae and L. gasseri [62]. Recently, Petrova et al. have showed that $L$. iners has more complex nutritional requirements and a Gram-variable morphology when compared to other Lactobacillus species [49]. Genome sequencing revealed that $L$. iners has an unusually small genome indicative of a parasitic or symbiotic lifestyle in the human vagina, which encodes inerolysin, a pore-forming toxin related to vaginolysin of G. vaginalis [49]. Similar to our previous studies, the Lactobacillus species, such as L. iners and L. crispatus, maintained the balance of the vaginal ecosystem, while these vaginal pathogenic bacteria contributed to the dysbiosis of the vaginal microbiota $[19,57,58]$. The depletion of lactobacilli, together with the increase of different species of anaerobes, could result in the switch from normal to a dysbiosis vaginal microbiota, which contributed to various adverse outcomes.

Our findings could have important implications when interpreting the varied results of investigations aimed at improving pregnancy outcomes. These data support the observation that the prevalence of vaginal microbiota varies significantly over the course of pregnancy, with a strong trend towards a reduction in infection by the third trimester. The limitation of this study is small sample capacity and nonlongitudinal design.

\section{Conclusion}

In summary, we investigated the changes of laboratory characteristics and the presence of certain bacteria in the vagina throughout pregnancy and highlighted their relationship. L. iners was found to be significantly decreased in the second and third trimester compared with the first trimester, while L. crispatus increased only in the second trimester. It was found that $L$. iners may be highly associated with vaginal dysbiosis, and further research studies are required to identify it. Additionally, quantification of the relative and absolute numbers of $L$. iners under different conditions throughout pregnancy was needed to be able to potentially predict adverse outcomes that it may be associated with. This study was limited due to the relatively small sample size $(n=83)$; however, it did provide the basis of future work to investigate the role of the microbiota in both low- and high-risk pregnancies.

\section{Data Availability}

The data used to support the findings of this study are available from the corresponding author upon request.

\section{Conflicts of Interest}

The authors declare no potential conflicts of interest with respect to the research, authorship, and/or publication of this article.

\section{Authors' Contributions}

$\mathrm{NZ}$ and RG contributed equally to this work. NZ and ZL conceived and designed the study. NZ, RG, YY, and MJ collected the samples. YC and ZL performed qPCR. NZ, RG, $\mathrm{YC}$, and ZL analyzed the data, carried out the computational analysis, interpreted the data, and drafted the manuscript.

\section{Acknowledgments}

The authors gratefully acknowledge the volunteers who participated in our study. This work was supported by the Science and Technology Foundation of Public Welfare Profession of Zhejiang Province (grant no. 2015C33198), the Medical Science and Technology Project of Zhejiang Province (grant no. 2017KY337), the National S \& T Major Project of China (2018YFC2000500), and the National Natural Science Foundation of China (81771724, 31700800, 81790633, and 31870839).

\section{Supplementary Materials}

Table S1: judgment method of vaginal cleanliness. (Supplementary Materials)

\section{References}

[1] B. Ma, L. J. Forney, and J. Ravel, "Vaginal microbiome: rethinking health and disease," Annual Review of Microbiology, vol. 66, no. 1, pp. 371-389, 2012.

[2] R. Romero, S. S. Hassan, P. Gajer et al., "The vaginal microbiota of pregnant women who subsequently have spontaneous preterm labor and delivery and those with a normal delivery at term," Microbiome, vol. 2, no. 1, p. 18, 2014.

[3] A. Machado, C. Almeida, D. Salgueiro et al., "Fluorescence in situ Hybridization method using Peptide nucleic acid probes for rapid detection of Lactobacillus and Gardnerella spp.," BMC Microbiology, vol. 13, no. 1, p. 82, 2013. 
[4] S. M. Husain, M. Wilks, M. Mupita et al., "Diversity and stability of cultured vaginal lactobacilli in pregnant women from a multi-ethnic urban UK population," Journal of Applied Microbiology, vol. 117, no. 1, pp. 258-265, 2014.

[5] C. Tellapragada, V. K. Eshwara, P. Bhat, A. Kamath, S. Aletty, and C. Mukhopadhyay, "Screening of vulvovaginal infections during pregnancy in resource constrained settings: implications on preterm delivery," Journal of Infection and Public Health, vol. 10, no. 4, pp. 431-437, 2017.

[6] R. Vigneswaran, "Infection and preterm birth: evidence of a common causal relationship with bronchopulmonary dysplasia and cerebral palsy," Journal of Paediatrics and Child Health, vol. 36, no. 4, pp. 293-296, 2000.

[7] J. van Dillen, J. Zwart, J. Schutte, and J. van Roosmalen, "Maternal sepsis: epidemiology, etiology and outcome," Current Opinion in Infectious Diseases, vol. 23, no. 3, pp. 249-254, 2010.

[8] D. Drassinower, A. M. Friedman, S. G. Obican, H. Levin, and C. Gyamfi-Bannerman, "Prolonged latency of preterm premature rupture of membranes and risk of cerebral palsy," The Journal of Maternal-Fetal \& Neonatal Medicine, vol. 29, no. 17, pp. 2748-2752, 2015.

[9] H. Lu, Q. Wang, J. Lu, Q. Zhang, and P. Kumar, "Risk factors for intraventricular hemorrhage in preterm infants born at 34 Weeks of gestation or less following preterm premature rupture of membranes," Journal of Stroke and Cerebrovascular Diseases, vol. 25, no. 4, pp. 807-812, 2016.

[10] K. Puri, D. H. Taft, N. Ambalavanan, K. R. Schibler, A. L. Morrow, and S. G. Kallapur, "Association of chorioamnionitis with aberrant neonatal gut colonization and adverse clinical outcomes," PLoS One, vol. 11, no. 9, Article ID e0162734, 2016.

[11] E. Faure, K. Faure, M. Figeac et al., "Vaginal mucosal homeostatic response may determine pregnancy outcome in women with bacterial vaginosis: a pilot study," Medicine, vol. 95, no. 5, p. e2668, 2016.

[12] S. L. Hillier, R. P. Nugent, D. A. Eschenbach et al., "Association between bacterial vaginosis and preterm delivery of a low-birth-weight infant," New England Journal of Medicine, vol. 333, no. 26, pp. 1737-1742, 1995.

[13] C. A. Flynn, A. L. Helwig, and L. N. Meurer, "Bacterial vaginosis in pregnancy and the risk of prematurity: a metaanalysis," The Journal of Family Practice, vol. 48, no. 11, pp. 885-892, 1999.

[14] D. B. DiGiulio, B. J. Callahan, P. J. McMurdie et al., "Temporal and spatial variation of the human microbiota during pregnancy," Proceedings of the National Academy of Sciences, vol. 112, no. 35, pp. 11060-11065, 2015.

[15] L. M. Kindinger, D. A. MacIntyre, Y. S. Lee et al., "Relationship between vaginal microbial dysbiosis, inflammation, and pregnancy outcomes in cervical cerclage," Science Translational Medicine, vol. 8, no. 350, p. 350ra102, 2016.

[16] G. Reid, J. A. Younes, H. C. Van der Mei, G. B. Gloor, R. Knight, and H. J. Busscher, "Microbiota restoration: natural and supplemented recovery of human microbial communities," Nature Reviews Microbiology, vol. 9, no. 1, pp. 27-38, 2011.

[17] R. Romero, S. S. Hassan, P. Gajer et al., "The composition and stability of the vaginal microbiota of normal pregnant women is different from that of non-pregnant women," Microbiome, vol. 2, no. 1, 2014.

[18] A. McMillan, S. Rulisa, M. Sumarah et al., "A multi-platform metabolomics approach identifies highly specific biomarkers of bacterial diversity in the vagina of pregnant and non- pregnant women," Scientific Reports, vol. 5, no. 1, p. 14174, 2015.

[19] X. Z. Ling, M. J. Kong, F. Liu et al., "Molecular analysis of the diversity of vaginal microbiota associated with bacterial vaginosis," BMC Genomics, vol. 11, no. 1, p. 488, 2010.

[20] A. Shobokshi and M. Shaarawy, "Maternal serum and amniotic fluid cytokines in patients with preterm premature rupture of membranes with and without intrauterine infection," International Journal of Gynecology \& Obstetrics, vol. 79, no. 3, pp. 209-215, 2002.

[21] K. B. Fortner, C. A. Grotegut, C. E. Ransom et al., "Bacteria localization and chorion thinning among preterm premature rupture of membranes," PLoS One, vol. 9, no. 1, Article ID e83338, 2014.

[22] V. V. Demkin, S. I. Koshechkin, and A. Slesarev, "A novel real-time PCR assay for highly specific detection and quantification of vaginal lactobacilli," Molecular and Cellular Probes, vol. 32, pp. 33-39, 2017.

[23] R. Verhelst, H. Verstraelen, G. Claeys et al., "Cloning of $16 \mathrm{~S}$ rRNA genes amplified from normal and disturbed vaginal microflora suggests a strong association between Atopobium vaginae, Gardnerella vaginalis and bacterial vaginosis," BMC Microbiology, vol. 4, no. 1, p. 16, 2004.

[24] D. H. Yan, Z. Lu, and J. R. Su, "Comparison of main Lactobacillus species between healthy women and women with bacterial vaginosis," Chinese Medical Journal, vol. 122, no. 22, pp. 2748-2751, 2009.

[25] R. Amsel, P. A. Totten, C. A. Spiegel, K. C. S. Chen, D. Eschenbach, and K. K. Holmes, "Nonspecific vaginitis," The American Journal of Medicine, vol. 74, no. 1, pp. 14-22, 1983.

[26] S. Kovachev, "Vaginal ecosystem," Akush Ginekol, vol. 50, no. 3, pp. 41-49, 2011.

[27] X.-A. Yue, P. Chen, Y. Tang, X. Wu, and Z. Hu, "The dynamic changes of vaginal microecosystem in patients with recurrent vulvovaginal candidiasis: a retrospective study of 800 patients," Archives of Gynecology and Obstetrics, vol. 292, no. 6, pp. 1285-1294, 2015.

[28] J. S. Lipp, Y. Morono, F. Inagaki, and K.-U. Hinrichs, "Significant contribution of Archaea to extant biomass in marine subsurface sediments," Nature, vol. 454, no. 7207, pp. 991-994, 2008.

[29] H. G. H. J. Heilig, E. G. Zoetendal, E. E. Vaughan, P. Marteau, A. D. L. Akkermans, and W. M. de Vos, "Molecular diversity of Lactobacillus spp. and other lactic acid bacteria in the human intestine as determined by specific amplification of $16 \mathrm{~S}$ ribosomal DNA," Applied and Environmental Microbiology, vol. 68, no. 1, pp. 114-123, 2002.

[30] R. Byun, M. A. Nadkarni, K.-L. Chhour, F. E. Martin, N. A. Jacques, and N. Hunter, "Quantitative analysis of diverse Lactobacillus species present in advanced dental caries," Journal of Clinical Microbiology, vol. 42, no. 7, pp. 3128-3136, 2004.

[31] R. Tamrakar, T. Yamada, I. Furuta et al., "Association between Lactobacillus species and bacterial vaginosis-related bacteria, and bacterial vaginosis scores in pregnant Japanese women," BMC Infectious Diseases, vol. 7, no. 1, p. 128, 2007.

[32] M. J. Ferris, A. Masztal, K. E. Aldridge, J. D. Fortenberry, P. L. Fidel Jr., and D. H. Martin, "Association of Atopobium vaginae, a recently described metronidazole resistant anaerobe, with bacterial vaginosis," BMC Infectious Diseases, vol. 4, no. 5, 2004.

[33] M. Zariffard, M. Saifuddin, B. E. Sha, and G. T. Spear, "Detection of bacterial vaginosis-related organisms by real- 
time PCR for Lactobacilli, Gardnerella vaginalis and Mycoplasma hominis," FEMS Immunology and Medical Microbiology, vol. 34, no. 4, pp. 277-281, 2002.

[34] D. N. Fredricks, T. L. Fiedler, and J. M. Marrazzo, "Molecular identification of bacteria associated with bacterial vaginosis," New England Journal of Medicine, vol. 353, no. 18, pp. 1899-1911, 2005.

[35] F. E. Martin, M. A. Nadkarni, N. A. Jacques, and N. Hunter, "Quantitative microbiological study of human carious dentine by culture and real-time PCR: association of anaerobes with histopathological changes in chronic pulpitis," Journal of Clinical Microbiology, vol. 40, no. 5, pp. 1698-1704, 2002.

[36] X. Zhou, C. J. Brown, Z. Abdo et al., "Differences in the composition of vaginal microbial communities found in healthy Caucasian and black women," The ISME Journal, vol. 1, no. 2, pp. 121-133, 2007.

[37] H. Verstraelen, R. Verhelst, G. Claeys, E. De Backer, M. Temmerman, and M. Vaneechoutte, "Longitudinal analysis of the vaginal microflora in pregnancy suggests that $L$. crispatus promotes the stability of the normal vaginal microflora and that L. gasseri and/or L. iners are more conducive to the occurrence of abnormal vaginal microflora," $B M C$ Microbiology, vol. 9, no. 1, p. 116, 2009.

[38] S. I. Pavlova, A. O. Kilic, S. S. Kilic et al., "Genetic diversity of vaginal Lactobacilli from women in different countries based on 16S rRNA gene sequences," Journal of Applied Microbiology, vol. 92, no. 3, pp. 451-459, 2002.

[39] M. Tärnberg, T. Jakobsson, J. Jonasson, and U. Forsum, "Identification of randomly selected colonies of Lactobacilli from normal vaginal fluid by pyrosequencing of the $16 \mathrm{~S}$ rDNA variable V1 and V3 regions," APMIS, vol. 110, no. 11, pp. 802-810, 2002.

[40] T. P. Waters, J. M. Denney, L. Mathew, R. L. Goldenberg, and J. F. Culhane, "Longitudinal trajectory of bacterial vaginosis during pregnancy," American Journal of Obstetrics and Gynecology, vol. 199, no. 4, pp. 431 e431-e435, 2008.

[41] P. Duff, M. L. Lee, S. L. Hillier, L. M. Herd, M. A. Krohn, and D. A. Eschenbach, "Amoxicillin treatment of bacterial vaginosis during pregnancy," Obstetrics \& Gynecology, vol. 77, no. 3, pp. 431-435, 1991.

[42] J.-S. Ryu and D.-Y. Min, "Trichomonas vaginalis and trichomoniasis in the Republic of Korea," The Korean Journal of Parasitology, vol. 44, no. 2, pp. 101-116, 2006.

[43] D. Nenadic and M. Pavlovic, "Value of bacterial culture of vaginal swabs in diagnosis of vaginal infections," Vojnosanitetski Pregled, vol. 72, no. 6, pp. 523-528, 2015.

[44] C. Mitchell, D. Fredricks, K. Agnew, and J. Hitti, "Hydrogen peroxide-producing Lactobacilli are associated with lower levels of vaginal interleukin-1 $\beta$, independent of bacterial vaginosis," Sexually Transmitted Diseases, vol. 42, no. 7 , pp. 358-363, 2015.

[45] M. Vaneechoutte, "Lactobacillus iners, the unusual suspect," Research in Microbiology, vol. 168, no. 9-10, pp. 826-836, 2017.

[46] J. M. Macklaim, A. D. Fernandes, J. M. Di Bella, J. A. Hammond, G. Reid, and G. B. Gloor, "Comparative meta-RNA-seq of the vaginal microbiota and differential expression by Lactobacillus iners in health and dysbiosis," Microbiome, vol. 1, no. 1, p. 12, 2013.

[47] H. Borgdorff, S. D. Armstrong, H. L. Tytgat et al., "Unique insights in the cervicovaginal Lactobacillus iners and $L$. Crispatus proteomes and their associations with microbiota dysbiosis," PLoS One, vol. 11, no. 3, Article ID e0150767, 2016.

[48] M. Zozaya-Hinchliffe, R. Lillis, D. H. Martin, and M. J. Ferris, "Quantitative PCR assessments of bacterial species in women with and without bacterial vaginosis," Journal of Clinical Microbiology, vol. 48, no. 5, pp. 1812-1819, 2010.

[49] M. I. Petrova, G. Reid, M. Vaneechoutte, and S. Lebeer, "Lactobacillus iners: friend or foe?," Trends in Microbiology, vol. 25, no. 3, pp. 182-191, 2017.

[50] L. M. Kindinger, P. R. Bennett, Y. S. Lee et al., "The interaction between vaginal microbiota, cervical length, and vaginal progesterone treatment for preterm birth risk," Microbiome, vol. 5, no. 1, p. 6, 2017.

[51] L. Petricevic, K. J. Domig, F. J. Nierscher et al., "Characterisation of the vaginal Lactobacillus microbiota associated with preterm delivery," Scientific Reports, vol. 4, no. 1, p. 5136, 2014.

[52] P. Gajer, R. M. Brotman, G. Bai et al., "Temporal dynamics of the human vaginal microbiota," Science Translational Medicine, vol. 4, no. 132, p. 132ra52, 2012.

[53] S. Srinivasan, C. Liu, C. M. Mitchell et al., "Temporal variability of human vaginal bacteria and relationship with bacterial vaginosis," PLoS One, vol. 5, no. 4, Article ID e10197, 2010.

[54] S. Y. Doerflinger, A. L. Throop, and M. M. Herbst-Kralovetz, "Bacteria in the vaginal microbiome alter the innate immune response and barrier properties of the human vaginal epithelia in a species-specific manner," The Journal of Infectious Diseases, vol. 209, no. 12, pp. 1989-1999, 2014.

[55] Y. Feng, Z. Yao, and D. J. Klionsky, "How to control selfdigestion: transcriptional, post-transcriptional, and posttranslational regulation of autophagy," Trends in Cell Biology, vol. 25, no. 6, pp. 354-363, 2015.

[56] B. Levine, N. Mizushima, and H. W. Virgin, "Autophagy in immunity and inflammation," Nature, vol. 469, no. 7330, pp. 323-335, 2011.

[57] Z. X. Ling, X. Liu, Y. Q. Luo et al., “Associations between vaginal pathogenic community and bacterial vaginosis in Chinese reproductive-age women," PLoS One, vol. 8, no. 10, Article ID e76589, 2013.

[58] Z. Ling, X. Liu, W. Chen et al., "The restoration of the vaginal microbiota after treatment for bacterial vaginosis with metronidazole or probiotics," Microbial Ecology, vol. 65, no. 3, pp. 773-780, 2013.

[59] C. S. Bradshaw, S. N. Tabrizi, C. K. Fairley, A. N. Morton, E. Rudland, and S. M. Garland, "The association of Atopobium vaginae and Gardnerella vaginalis with bacterial vaginosis and recurrence after oral metronidazole therapy," The Journal of Infectious Diseases, vol. 194, no. 6, pp. 828-836, 2006.

[60] B. B. Oakley, T. L. Fiedler, J. M. Marrazzo, and D. N. Fredricks, "Diversity of human vaginal bacterial communities and associations with clinically defined bacterial vaginosis," Applied and Environmental Microbiology, vol. 74, no. 15, pp. 4898-4909, 2008.

[61] M. Zozaya-Hinchliffe, D. H. Martin, and M. J. Ferris, "Prevalence and abundance of uncultivated Megasphaera-like bacteria in the human vaginal environment," Applied and Environmental Microbiology, vol. 74, no. 5, pp. 1656-1659, 2008.

[62] E. De Backer, R. Verhelst, H. Verstraelen et al., "Quantitative determination by real-time PCR of four vaginal Lactobacillus species, Gardnerella vaginalis and Atopobium vaginae indicates an inverse relationship between L. gasseri and L. iners," BMC Microbiology, vol. 7, no. 1, p. 115, 2007. 


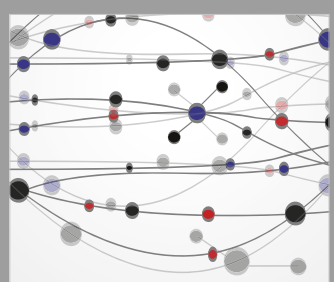

The Scientific World Journal
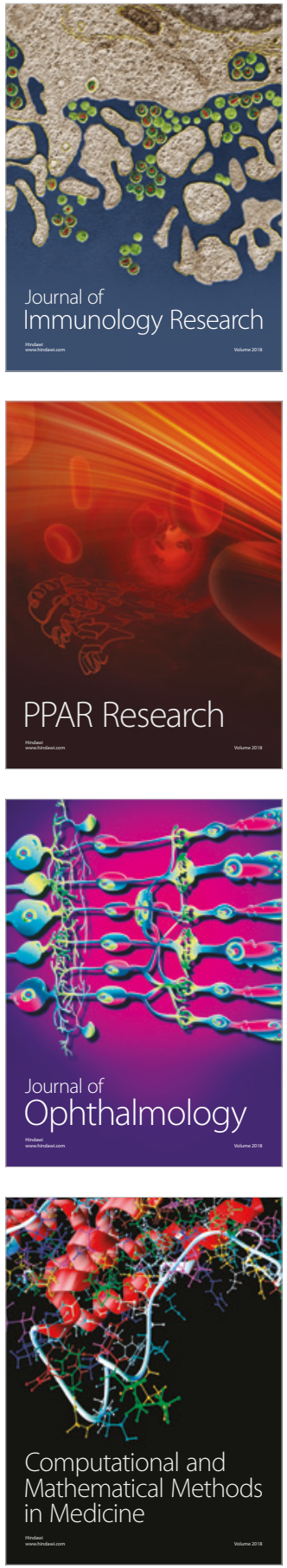

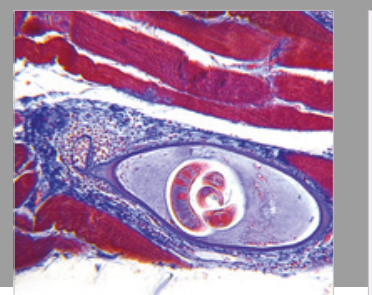

Gastroenterology Research and Practice

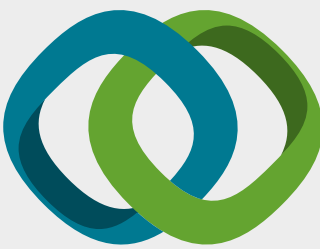

\section{Hindawi}

Submit your manuscripts at

www.hindawi.com
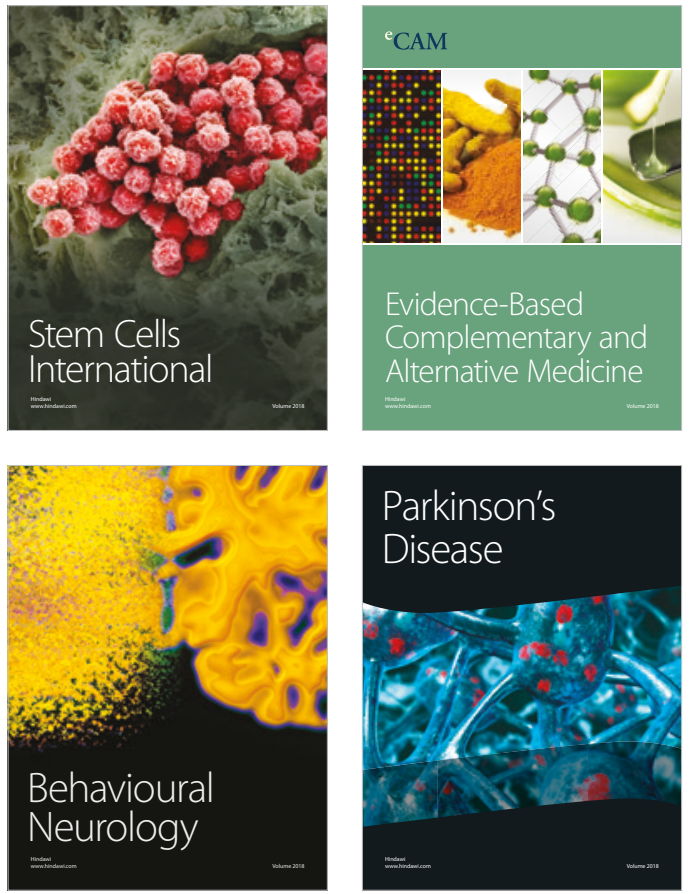

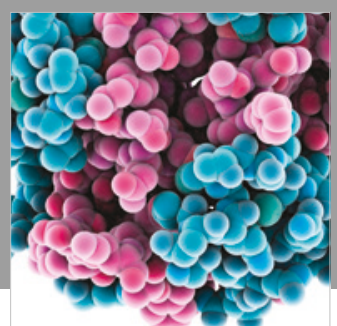

ournal of

Diabetes Research

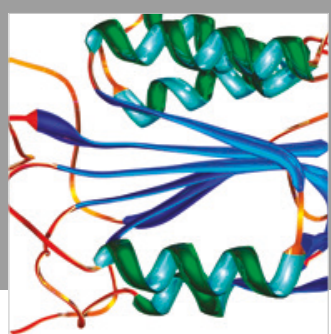

Disease Markers
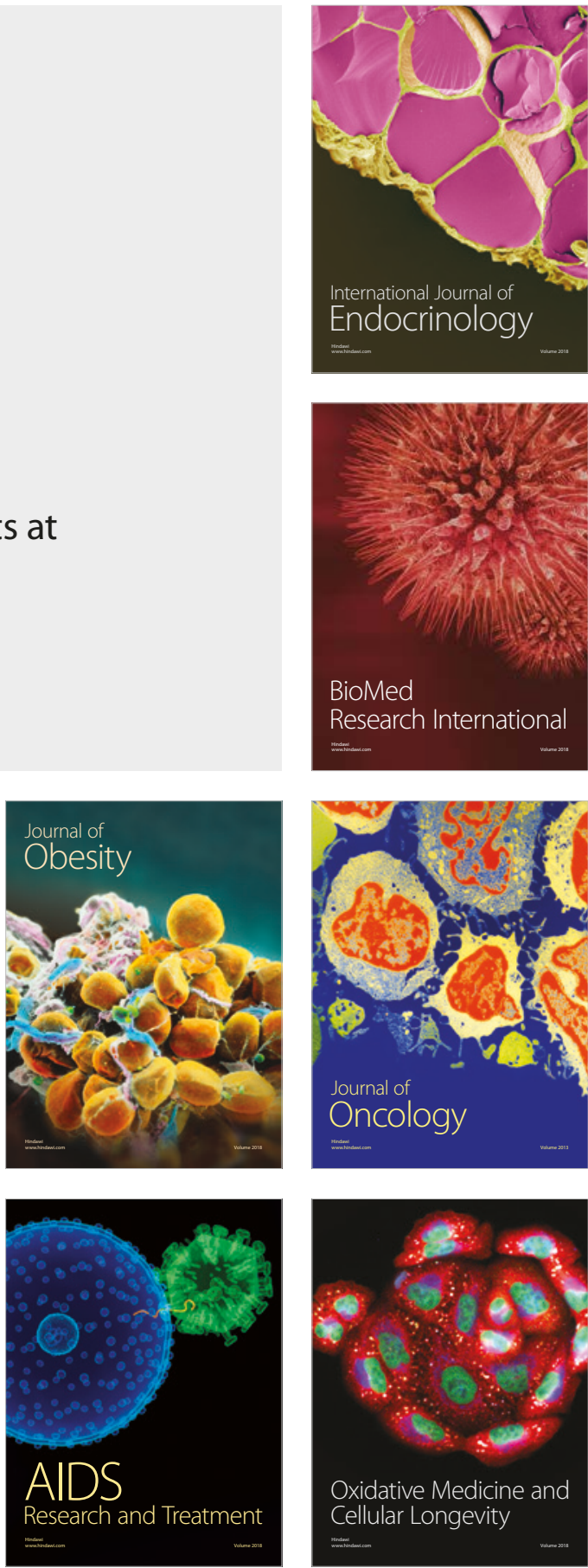